Critical Studies in Improvisation / Études critiques en improvisation, Vol. 12, No. 2

\title{
Improvising Through Trauma
}

\section{Neelamjit Dillon}

On August 5, 2012 a gunman walked into a Sikh gurdwara (house of worship) and opened fire on the congregation, resulting in the deaths of six innocent people. This act did not take place in a war-torn community with deeply entrenched sectarian violence; it happened in America, in the town of Oak Creek, Wisconsin. This event shook the North American and worldwide Sikh communities, and led to widespread uncertainty and fear. In the aftermath of such an event, how does one come to deal with the immediate and long-term effects of trauma, and what tools can be used to address this issue? For myself, a musician and a Sikh, a solo saxophone improvisation was the preferred means by which to frame a response to this tragedy. This artistic expression served not only as a vehicle to respond to this sensless act, but also as a means of addressing a community left in disbelief, and as a way to educate those unaware of the tragedy.

Media coverage of this particular shooting was minimal, leaving many from outside the Sikh community oblivious to the fact that a hate crime had even occured. Naunihal Singh, an assistant professor of political science at the University of Notre Dame, argues in the New Yorker that, as a result of the lack of coverage, "the massacre in Oak Creek is treated as a tragedy for Sikhs in America rather than a tragedy for all Americans." Although the Oak Creek shooting occurred only two weeks after the movie theater shooting in Aurora, Colorado, it received far less coverage and very few statements from public figures. In the statement released by the White House, President Barack Obama referred to the Sikh community as "a part of our broader American family" (emphasis added). Sikhs have been a part of the American family for over a century, but are still not seen as an equal part of the American experience. The response by the media and the comments from the president only served to further ostracize an already marginalized segment of the population. This paper seeks to place the Oak Creek shooting in the context of the larger Sikh struggle and to illuminate the inherent trauma involved in that struggle. It also seeks to show how improvisation can serve as a means to address such trauma, which I have sought to do through my original musical work Wisconsin.

\section{Sikh Struggle}

Sikhism emerged in India in the late 1400s as a reaction to Hinduism and Islam. Although it is a religion that champions social justice, gender equality, and community service, its followers have been marginalized and have had to endure brutality since its inception. Of Sikhism's lineage of ten living prophets, two were tortured and killed with horrific brutality at the hands of the Mogul emperors of India. There have been systematic attempts at eradicating the Sikhs, as in the early 1700s when a price was placed on their heads, which led to Sikhs being hunted and slaughtered for profit (K. Singh 127-129). In 1984, Prime Minister Indira Gandhi sent the Indian army to the Golden Temple in Amritsar, the holiest Sikh shrine, in an attempt to hunt down so called "militants." Tanks were driven into the temple complex, and army troops opened fire on the congregation, resulting in innocent people being murdered by their own government and the temple complex left in ruin. In reaction to this brutality, Indira Gandhi was assassinated by her two Sikh bodyguards, setting off mass violence against Sikhs in New Delhi and throughout India. These pogroms, instigated by the police and the government, resulted in barbaric riots and the wholesale slaughter of thousands of Sikhs. In Punjab from the mid-1980s to the mid1990s, police apprehended young Sikh men under the guise of stamping out militancy (Axel). 
Critical Studies in Improvisation / Études critiques en improvisation, Vol. 12, No. 2

These innocent men were taken, tortured, and killed; the majority of their bodies were never recovered.

Hatred and fear followed the Sikh community even as they emigrated out of India in search of a better life in other countries. The history of Sikhs in North America is laden with racism and xenophobic attitudes. The Bellingham riots of 1907 (Zhao and Park 141) and the Komagata Maru incident of 1914 (Kazimi) demonstrate the hatred and fear toward immigrants coming to Canada and America. Laws prevented immigrants from becoming full citizens, and racist attitudes persisted amongst the white members of society-immigrants themselves only a few generations earlier. Even today, most Americans are unaware of the Sikh community, even though it has been in North America for over a hundred years (Dhillon).

In the aftermath of the attack on the World Trade Centre in New York City on September 11, 2001, even before anyone had claimed responsibility for the terrorist act, Sikhs were the targets of hate crimes all over the US. This violence lead to the murder of Balbir Singh Sodhi in Arizona only five days after $9 / 11$. Sodhi's murder, perpetrated by a vigilante who claimed to be a patriot, was largely lost among the national tragedy of the collapse of the twin towers (J. Singh 2). Sadly, this type of incident was nothing new for Sikhs, who have continuously faced hate crimes in retaliation to the Iran Contra incident and the Gulf War (Divided We Fall).

Hate crimes against Sikhs continue to be perpetrated throughout the United States and around the globe. In November 2007, a taxi driver in Seattle was assaulted by his own passenger; he was called a terrorist, severely beaten, and had his scalp bitten (Sullivan and Clarridge). In August 2012, a gunman opened fire in a Sikh gurdwara in Wisconsin (Schwirtz et al.), killing six innocent members of the congregation. In the spring of 2013 the Quebec Soccer Federation banned any youths wearing a turban from playing on the field (Tandt). In September 2013, a judge in Mississippi told a Sikh truck driver to remove the "rag" from his head before entering his courtroom (Atwood) and a Sikh professor at Columbia University in New York was severely beaten and had his jaw fractured by a gang of a dozen or more young men (Goodman). In July 2014, two players from team India were asked to remove their turbans before competing at the Asia Cup in China, as per the International Basketball Federation's (FIBA) discriminatory ban on headwear (De Bode). Also in July 2014, in Queens, New York, Sandeep Singh was called a terrorist and told to go back to his country before being run over by a truck, dragged for thirty feet, and left to die (CBS New York). These events, which are only a few examples of discriminatory policies and hate crimes perpetuated against Sikhs, point to an endemic problem that needs addressing.

In the summer of 2013, the Stanford Peace Innovation Lab put out a first-of-its-kind study about the perceptions surrounding the Sikh American community. The study, "Turban Myths: The Opportunity and Challenges for Reclaiming a Cultural Symbol for Post 9/11 America," grew out of concerns in the aftermath of the 2012 Oak Creek, Wisconsin shooting, and highlights the challenges Sikh Americans have faced since 9/11. Some of the key results of the study found that Americans tend to associate turbans with Osama bin Laden, that $49 \%$ of Americans believe "Sikh" is a sect of Islam, that $79 \%$ cannot identify India as the geographic origin of Sikhism, and that an anti-turban bias exists even among people with a greater knowledge of Sikhs (Standford Peace Innovation Lab 4). The turban has been branded negatively in the psyche of many Americans, and it is only through greater understanding that the Sikh community can hope to overcome this bias.

Another report, titled "Go Home Terrorist," highlights the high rates of bullying in schools against Sikh children. The report based its finding on surveys, focus groups, and interviews of 
approximately 1200 Sikh students in the states of Massachusetts, Indiana, Washington, and California. The findings show that just over $50 \%$ endure school bullying, and that for turbaned Sikh children the percentage is $67 \%$-more than double the national rate (Sikh Coalition 4 ). The report goes on to make recommendations to Congress, to the Department of Education, to state boards of education, as well as to teachers and administrators about how to deal with this very real and serious issue.

Although I was born in Canada, I grew up amidst the generational trauma of Sikhs in India, and with the knowledge of hate crimes committed in North America. Realizing my place within a marginalized community has been difficult, and I have gravitated towards jazz as a way to make sense of it. The experience of musicians, especially African-Americans during the civil rights movement, was a way to start making sense of my own condition. Playing jazz in school bands led me to discover the political undertones in the music, which gave voice to a movement and galvanized a people. Through jazz and creative music, I found an artistic voice through which to understand my own identity and to express the Sikh experience.

\section{Trauma}

For Sikhs in North America, a diasporic community that has fled the generational trauma of India, the Oak Creek shooting was one of the most heinous acts of violence and hatred taken against them. The community was just starting to feel less vilified from the hatred that had ensued post 9/11, but the Oak Creek incident made Sikhs feel like targets once again. In light of such events, how does trauma manifest and how can one hope to combat it?

Trauma is a complex issue that manifests in many ways, but we can start to understand it by dividing it into two broad categories. Kai T. Erikson, noted authority on the social consequences of catastrophic events, calls the first category "individual trauma," defining it as "a blow to the psyche that breaks through one's defenses so suddenly and with such brutal force that one cannot react to it effectively" (153). For those directly involved in the Oak Creek attack, it is unimaginable to comprehend the sense of shock that must have resulted from having your sacred space desecrated, having community members physically and emotionally hurt, and from losing loved ones in a senseless and unexpected attack. The feeling of safety was ripped away, and individuals were left in disbelief and distress.

The second broad category that we can use to try and understand trauma is that of "collective trauma." This category can be defined as "a blow to the basic tissues of social life that damages the bonds attaching people together and impairs the prevailing sense of communality" (Erikson 154). For the worldwide Sikh community, the Oak Creek shooting tore at the fabric of communal relationships that had been formed over time. In places such as Canada, the United Kingdom, Kenya, India, and Thailand-places Sikhs have called home for generations and where they had become a part of the culture-the shooting made Sikhs the "other" once again. The lack of news coverage was devastating for those not in Oak Creek, as it was difficult to find out what had happened. One of the only ways to get information was by relying on social media posts from those who were actually there. For the global community, it was heartbreaking that this event was not deemed newsworthy. To see that this tragedy for the Sikh community was not treated as a tragedy for all served to deepen the feelings of separation and marginalization of Sikhs within the American framework.

These two categories, individual and collective, help define some parameters for understanding trauma. But it is a subject that is not so easily and clearly defined, as one does not simply feel trauma in solely an individual or collective way. For those in the Sikh community, collective and 
Critical Studies in Improvisation / Études critiques en improvisation, Vol. 12, No. 2

individual trauma were felt and experienced at the same time. There was the sense of communal isolation and "othering," but those experiences were also focused through each individual and their distinctive experiences and histories. For me, the feeling of becoming disjointed from my North American identity has been unsettling, and has motivated me to craft an improvisatory artistic response as an attempt at healing for myself and the community.

\section{Improvisation and Therapy}

There is perhaps no better way to capture the essence of a moment than improvisation. It is a unique act of creation that can never be produced or experienced in the same way as when it was made. Improvisation is a creative act anchored in the memory of the past-distant or more recent-but unique to the time and place of creation. To be rooted in the present so deeply can result in unexpected outcomes that may bring forth emotions and experiences from one's subconscious. These outcomes have served to form the basis of using improvisation as a tool for the treatment of trauma within the discipline of musical therapy.

The temporal nature of improvisation is perhaps one of the most central and important ideas of this discipline. In his book Improvisation, Derek Bailey states: "In all its roles and appearances, improvisation can be considered as the celebration of the moment" (142). To improvise is to engage fully within the present moment and to express it in a meaningful way. Bailey goes on to align the nature of improvisation with the nature of music itself, stating that "music is fleeting; its reality is its moment of performance. There might be documents that relate to that momentscore, recording, echo, memory-but only to anticipate it or recall it" (142). The act of creation in music is the very essence of the art form. Scores and recordings can help us recall the moments, but can never fully capture the essence of a performance. Through improvisation, the performer can reduce the effects of "anticipation" and "recall" in an effort to get as close as possible to the spirit of the moment.

To understand the nature of improvisation, it is useful to turn to other disciplines. Noted theatre academic and teacher Viola Spolin states that "[t]hrough spontaneity we are re-formed into ourselves. It creates an explosion that for the moment frees us from handed-down frames of reference, memory choked with old facts and information and undigested theories and techniques of other people's findings" (4). Of particular note is Spolin's notion of freeing oneself from memory, which is also pertinent to the discussion of trauma. Improvisation is a way to engage in an act of spontaneity and to create something in the present moment that both reflects and transcends our personal histories and traumatic memories.

Within the realm of music therapy, improvisation has been used as a useful method for healing trauma, as music therapist Julie P. Sutton argues: "[m]usic communicates where words fail. This makes it an ideal medium for working with those who have suffered psychological trauma" (274). The experience of trauma is not easily transmitted or conveyed through speech. If one is unable to articulate - or even understand - the effects of trauma they have experienced, they cannot even begin to heal. Improvisation is an approach that can help start a dialogue. Music therapist and author Diane Austin explains how "improvisation can shore up a weak inner structure in the psyche and help contain strong emotions, thus making it safer to express them." Through the act of improvisation, we have a means of expression by which to connect with traumatic events and create a safe space for communication.

The discussion of therapy and trauma often revolves around using improvisation as a means of bridging the unconscious and conscious minds. This bridging is characterized in the observation of "improvisational moments" and the emergence of the "relational unconscious" (Ringstrom 69). 
Critical Studies in Improvisation / Études critiques en improvisation, Vol. 12, No. 2

When the therapist and patient are engaged in spontaneous moments of improvisation and play, they can move toward a state where both understand something deeper than traditional, one-way introspective analysis, enabling the observation of that which was "unimagined, unthought, and unspoken" (Ringstrom 69). From case studies of treating trauma from sexual abuse with music therapy, Amir noted the "powerful role that improvising music might have in bringing up, dealing with and integrating memories ... into the client's conscious existence" (96). In a case study of music therapy from trauma related to the holocaust, improvisation was seen to have a central role in exploring, contemplating, and expressing the patient's life experiences (Clements-Cortes). From these examples, we see the power of improvisation in helping those suffering from trauma realize and uncover things from their unconscious. Only by uncovering these hidden details is one able to consider their impact and implications, leading to potential breakthroughs in the healing process.

\section{Creative Music and Trauma}

The connection between improvisation and its ability to speak to trauma is not merely relegated to the clinical environment of music therapy. When placed in an artistic context, the connection between improvisation and trauma has been observed and reflected in various works. The following examples contextualize improvisation and trauma together under the broad musical umbrella of creative music.

Jazz is known and generally understood to have a large improvised component, and the experience of the jazz musician has served as inspiration for novels. Toni Morrison's Jazz (1992) and Jackie Kay's Trumpet (1998) are two works of literary fiction that draw upon the connection between improvisation and trauma. Both novels use the subject matter of jazz and its improvisatory framework to address the trauma of death, grief, and loss through their character's solo improvisations. In her book Trauma Fiction, Anne Whitehead points out that improvisation enables "the characters to tell and retell their stories of the dead and transform traumatic memory into narrative memory" (143). Through repeated solo improvisations, the characters are able to able to recall various versions of the past, bring them into the present, and recall them in the social environment of performance. Through this "telling and retelling," the characters are able to let go of their traumatic pasts and are able to move forward in their lives. This poetic description, utilized by both authors, speaks to the powerful connection between improvisation and its ability to heal. Neither author is a musician, yet both their books utilize this similar concept, pointing to an underlying connection between improvisation and its ability to address trauma.

The experiences of musicians' lives, often traumatic in nature, can serve as inspiration for artistic work. Two albums by American free jazz violinist Billy Bang, Vietnam: Reflections (2005) and Vietnam: The Aftermath (2001), serve to address postwar trauma. Bang served as an infantryman and lieutenant in the Vietnam War, and upon his return to America became an active member in the Sun Ra Arkestra (Fischlin et al. 153). The names of the albums themselves, The Aftermath and Reflections, speak to the albums' intent and to their relationship not only to Bang's personal trauma, but to the trauma of many of the musicians involved in the project who were also veterans. These projects situate musicians and their music in acts of reflection and restoration, perhaps in an attempt to attain peace from their traumatic pasts.

Musicians' individual experiences are often an extension of the experiences of an entire group of people and can serve as the basis for a musical movement. Japanese internment and the treatment of Asian Americans post World War II were events that enraged and inspired what some refer to as the Asian American jazz movement. Many of their musics focused the 
traumatic events of their communities into musical expressions of avant-garde jazz. This group, influenced by Black Nationalism and driven to create an oppositional minority culture, includes musicians such as Jon Jang, Glenn Horiuchi, Francis Wong, Anthony Brown, Mark Izu, Fred Ho, and Jason Kao Hwang. Works such as Jang's Reparations Now!, Brown's E.O. 9066: Truth Be Told, and Soji Kashiwagi's The Camp Dance: The Music and the Memories show a clear emergence of a movement and represent different aspects and stages of the cultural trauma process (Hung). This work was deeply entrenched in the work of American jazz musicians advocating for civil rights, and Jang's title Reparations Now! is a direct reference to drummer Max Roach's album Freedom Now! The work of these musicians, situated in the collective trauma of the treatment of their community, has made use of the language of jazz and the technique of improvisation to address trauma as well as to heal from it.

My own work has been inspired by the work of jazz and creative musicians who use their artwork to speak towards trauma. Artist-activist Nina Simone has said that, "[a]n artist's duty ... is to reflect the times" ("Nina Simone"). She was making reference to the civil rights movement in America, which comes out of the history of traumatic experiences of African Americans through slavery and segregation. The title of my own piece, Wisconsin, is a direct homage to saxophonist John Coltrane's piece Alabama, a work written as an elegy for the four young girls murdered in the 1963 bombing of a black church in Birmingham, Alabama by members of the Klu Klux Klan. Although I did not experience the Oak Creek shooting firsthand, I felt the trauma of the event and turned to improvisation and music as a means to express my own feelings and as a way to reflect, respond, and teach.

\section{Recovery and an Artistic Work}

Improvisation can help express unconscious feeling and emotion, which in turn can open paths toward the complex and challenging process of trauma recovery. Judith Lewis Herman, psychiatrist and author of Trauma and Recovery, codifies recovery from trauma as a threestage process:

The central task of the first stage is the establishment of safety. The central task of the second stage is remembrance and mourning. The central task of the third stage is reconnection with ordinary life. Like any abstract concept, these stages of recovery are a convenient fiction, not to be taken too literally. They are an attempt to impose simplicity and order upon a process that is inherently turbulent and complex. (Herman 155)

Herman herself realizes that this is an over-simplification of recovery, but these steps are a valuable tool for understanding this intricate and difficult process. These stages are reflected in my piece Wisconsin, and it is through them that the motivations for the work can be understood.

Herman's first stage of establishing safety is addressed in Wisconsin through the use of sonic vocabulary familiar to the Sikh experience. The piece opens with an audio sample of a tanpura, a lute instrument used in Indian classical music to produce a drone. This drone is a familiar sound to Sikhs and many South Asians, as it is used as the foundation for North and South Indian classical traditions, as well as kirtan, a devotional music that is a part of regular Sikh religious services. By opening with the sound of the tanpura, my intent is to establish a safe space through the familiarity of the sonic stimulus.

As the piece develops, the harmonic content is also based partly on familiar sounds from Indian classical music. The piece is built upon one of my own unique approaches to raag harmonization, which uses raags (melodic forms from Indian classical music) as source material 
for improvisation. In the piece, the initial drone sample continues through the duration of the composition, while other drones, built off all other chromatic pitches, are introduced and then fade away. As each pair of drones sound together, they create a sonic resultant which can be seen as a four-note chord, the basic harmonic framework in jazz. These unique chords suggest various raags to be used as the impetus for improvisation as each set of pitches highlights different harmonic stresses analogous to the important notes inherent in each raag. This approach was developed out of the concept of chord-tones and chord-scale relationships familiar to jazz musicians. Raags have certain characteristic melodic movement, providing recognizable and familiar sounds, which in turn provide familiarity and therefore a sense of safety.

Remembrance and mourning, the second step in Herman's process of trauma recovery, are central ideas that served as motivation in creating the piece. Using art as activism was necessary for telling this story, not only to help the community deal with the tragedy but also as a way to educate others about the plight of Sikhs in North America. I felt compelled to comment on this tragedy, but was unsure how to maintain the authenticity of the moment. Trauma author and scholar Cathy Caruth writes that

many people have recognized the urgency of learning more about the traumatic reaction to violent events and about the means of helping to alleviate suffering ... . [b]ut the study and treatment of trauma continues to face a crucial ... problem of how to help relieve suffering, and how to understand the nature of the suffering, without eliminating the force and truth of the reality that trauma survivors face. (vii)

Using art as a way to treat trauma was the artistic motivation and incorporating the use of real audio clips from the tragedy served as a way to speak to Caruth's notion of the "truth of reality."

Retelling the events surrounding the Oak Creek shooting through media clips depicts how events unfolded and also the subsequent reaction and reflection that emerged out of the tragedy. Wisconsin makes use of twenty-one media clips taken from various sources, such as police scanners, news reports, 911 dispatches, and interviews, all used to retell the events using the voices of actual witnesses. All clips were sourced from YouTube, a deliberate attempt to place the piece in the framework of the American experience and within the context of the first amendment, which guarantees freedom of speech and freedom of religion. The use of real audio was also an attempt to alleviate any false memory around the event and to recall the events using the voices that lived them.

The audio clips are interspersed with the various drone samples and provide harmonic material from which to render saxophone improvisations. The improvisation, in turn, is a real-time emotional reaction of the perfomer in the moment. Each of the audio clips and drones are triggered by the performer through the use of a custom built MIDI thumb controller, enabling the performer to determine the pacing of the improvised musical reflections surrounding each audio clip. Each time the piece has been performed, the various clips trigger different improvised responses, and all of the performances have been unique reflections and experiences.

Herman's third and final step in trauma recovery is the reconnection with ordinary life, addressed in Wisconsin by the progression of audio clips. The sequence of clips start with real audio from the day of the shooting, such as calls to 911, clips from police dispatch, and audio recorded from a police scanner. The clips then focus on the aftermath of the event including a news report about the recovery of Lieutenant Brian Murphy, who was shot multiple times while 
confronting the shooter. The final progression of clips recalls discussions that occurred after the shooting and provide reflection about the treatment and placement of Sikhs in American society.

The comments of award-winning filmmaker, civil rights activist, and Yale law school graduate Valarie Kaur are particularly poignant and serve as the final two audio clips used in the piece. In the aftermath of the tragedy, Kaur's comments given in interviews on CNN and in other media outlets served to provide much clarity and perspective. She placed the Oak Creek shooting within a culture of violence against difference and drew connections to other tragic shootings, such as those of Matthew Shepard, David Kato, and Trayvon Martin ("Combatting Hate"). In the final audio clip of the piece, Kaur states, "This is a moment that calls upon all Americans to recommit to this idea of a country devoted to religious pluralism, of respect, and of peace" ("Combatting Hate"). These final statements focus the discussion toward placing the Oak Creek shooting within a broader context of opposing hate with tolerance, and offer a call to bring this opposition to our everyday lives.

Performances of Wisconsin have helped various audiences to recall the events surrounding the shooting, not only as a way to speak to trauma but as a way to inform and educate as well. The piece premiered at the SikhLens Film Festival at Chapman University in November 2012, and was performed at the California Institute of the Arts (CalArts) on April 10, 2013 and October 8, 2013. The performance at the film festival, a predominantly Sikh space, was a way to directly address trauma in the community. Although jazz was not a form particularly familiar to the audience, the efficacy of improvisation was easily observable. There was a powerful silence following the performance, which indicated to me deep reflection and resonance with the audience. Some audience members commented afterwards on the sounds of different raags they recognized, and others thanked me for presenting such a needed and moving work.

The performances at CalArts, a predominantly non-Sikh space, were opportunities to reflect on the shooting, and also served to educate those who were unaware of the tragedy. For me, the SikhLens performance felt reflective, while the CalArts performances were more reactive. I felt a duty to present this work at CalArts to present a segment of America that the audience may not know of or interact with. At the time, I had been a student at CalArts for three years, and was aware that many of my fellow students and faculty did not even know who the Sikhs were, and in turn did not really know who I was either. After each performance, many audience members told me how the piece had deeply moved them, while others revealed their ignorance about the shooting.

\section{Conclusion}

Wisconsin takes a singular event from the history of trauma faced by the Sikh community and uses improvisation as a means of addressing individual and collective trauma. Improvisation acts as a celebration of the moment and as a catalyst to bring underlying, unconscious thoughts and emotions into the conscious mind and into the present moment. In this way, improvisation can serve a therapeutic role well-documented in the treatment of trauma from a music therapy approach. By examining Wisconsin through the lens of Herman's three-step approach to trauma recovery, light is shed on the motivation and process involved in creating the piece. By examining this particular act of violence and hate through real audio clips from the event, authenticity is brought to the retelling of the moments and discussion that surrounded the shooting at the time it happened. Through this process, the Oak Creek shooting is brought into a much wider frame of reference, highlighting the tragedy with a call to action of combating hate in the present. 
Critical Studies in Improvisation / Études critiques en improvisation, Vol. 12, No. 2

Through improvisation I have sought to express my experiences and emotions as they are happening: my own way to celebrate the moment. As Spolin says, "[s]pontaneity is the moment of personal freedom when we are faced with a reality and see it, explore it and act accordingly. In this reality the bits and pieces of ourselves function as an organic whole. It is the time of discovery, of experiencing, of creative expression" (4). Through this freeing expression, I hope to transcend the trauma of the past and focus it through healing in the present, with the hopes of promoting understanding and tolerance in the future.

\section{Works Cited}

Amir, Dorit. "Giving Trauma a Voice: The Role of Improvisational Music Therapy in Exposing, Dealing with and Healing a Traumatic Experience of Sexual Abuse." Music Therapy Perspectives 22.2 (2004): 96-103.

Atwood, Bear. "Judge to Sikh Man: Remove 'That Rag." American Civil Liberties Union, www.aclu.org/blog/racial-justice/judge-sikh-man-remove-rag. Accessed 27 May 2014.

Austin, Diane. The Healing Symbol: Sound, Song and Psychotherapy. Unpublished Master's Thesis, New York University, 1986.

Axel, Brian Keith. The Nation's Tortured Body: Violence, Representation, and the Formation of a Sikh "Diaspora." Duke UP, 2001.

Bailey, Derek. Improvisation: Its Nature And Practice In Music. Da Capo, 1993.

Caruth, Cathy. Trauma: Explorations in Memory. Johns Hopkins UP, 1995.

CBS New York. "Suspect Charged With Hate Crimes After Allegedly Hitting Sikh Man With Truck - CBS New York." http://newyork.cbslocal.com/2014/08/19/long-island-man-faceshate-crime-charges-in-queens-hit-and-run/. Acccesed 24 Aug. 2014.

Clements-Cortes, Amy. "Music to Shatter the Silence: A Case Study on Music Therapy, Trauma, and the Holocaust/La Musique Pour Briser Le Silence : Une Étude de Cas Sur La Musicothérapie, Les Traumatismes, et l'Holocauste." Canadian Journal of Music Therapy 14.1 (2008): 9-21.

"Combatting Hate in the Wake of the Sikh Shooting." YouTube, uploaded by Odyssey Impact, 8 Aug. 2012, https://youtu.be/sEmFi3Y1Fzk.

De Bode, Lisa. "Sikh Basketball Players Gain Congressional Support to Lift Ban on Turbans." Al Jazeera America, http://america.aljazeera.com/articles/2014/8/20/sikh-fiba-fifaturbanhijab.html. Accesed 24 Aug. 2014.

Dhillon, Mahinder Singh. A History Book of the Sikhs in Canada and California. Shromani Akali Dal Association of Canada, 1981.

Divided We Fall: Americans in the Aftermath. Directed by Sharat Raju, written by Valarie Kaur. 2006.

Erikson, Kai T. Everything in Its Path: Destruction of Community in the Buffalo Creek Flood. Simon \& Schuster, 1978. 
Critical Studies in Improvisation / Études critiques en improvisation, Vol. 12, No. 2

Fischlin, Daniel, et al. The Fierce Urgency of Now: Improvisation, Rights, and the Ethics of Cocreation. Duke UP, 2013.

Goodman, J. David. "Chronicling Anti-Sikh Violence, and Now a Victim.” The New York Times, 23 Sept. 2013, https://www.nytimes.com/2013/09/24/nyregion/chronicling-anti-sikhviolence-and-now-a-victim.html. Accessed 27 May 2014.

Herman, Judith Lewis. Trauma and Recovery. Basic Books, 1997.

Hung, Eric. "Sounds of Asian American Trauma and Cultural Trauma: Jazz Reflections on the Japanese Internment." MUSICultures 39.2 (2012): 1-29.

Kazimi, Ali. Undesirables: White Canada and the Komagata Maru - An Illustrated History. Douglas \& Mclntyre, 2012.

"Nina Simone: An Artist's Duty." YouTube, uploaded by the estate of Nina Simone, 21 Feb., 2013, https://youtu.be/99V0mMNf5fo.

Obama, Barack. "Statement by the President on the Shooting in Wisconsin." The White House, 5 Aug. 2012, https://obamawhitehouse.archives.gov/the-press-office/2012/08/05/ statement-president-shooting-wisconsin. Accesed 24 May 2015.

Ringstrom, P. "Scenes That Write Themselves: Improvisational Moments in Relational Psychoanalysis.” Psychoanalytic Dialogues 17.1: 69-99.

Schwirtz, Steven, et al. "Gunman Kills 6 at Sikh Temple in Wisconsin." The New York Times, 5 Aug. 2012, https://www.nytimes.com/2012/08/06/us/shooting-reported-at-temple-inwisconsin.html. Accessed 27 May 2014.

Sikh Coalition. "Go Home Terrorist: A Report on Bullying Against Sikh American School Children." The Sikh Coalition, 2014.

Singh, Jaideep. "Memory, Invisibility, and the Oak Creek Gurdwara Massacre." Sikh Formations $9.2(2013): 215-225$.

Singh, Kushwant. A History of the Sikhs: 1469-1839. Oxford UP, 1986.

Singh, Naunihal. “An American Tragedy.” The New Yorker, 13 Aug. 2012, https://www.newyorker.com/news/news-desk/an-american-tragedy. Accessed 24 May 2015.

Spolin, Viola. Improvisation for the Theater: A Handbook of Teaching and Directing Techniques. Northwestern UP, 1983.

Stanford Peace Innovation Lab. "Turban Myths: The Opportunity and Challenges for Reframing a Cultural Symbol for Post 9/11 America." Stanford Peace Innovation Lab, 2013.

Sullivan, Jennifer, and Christine Clarridge. "Man Sentenced for Attack on Seattle Cab Driver." The Seattle Times, 18 Apr. 2008, https://www.seattletimes.com/seattle-news/mansentenced-for-attack-on-seattle-cab-driver/. Accssed 27 May 2014. 
Sutton, Julie P. Music, Music Therapy and Trauma: International Perspectives. Jessica Kingsley Publishers, 2002.

Tandt, Michael Den. "Michael Den Tandt: Turban Ban Shamefully Stupid." Montreal Gazette, 4 Jun. 2013, www.montrealgazette.com/life/Michael+Tandt+Turban+shamefully+stupid/ 8478239/story.html. Accessed 27 May 2014.

Whitehead, Anne. Trauma Fiction. Edinburgh UP, 2004.

Zhao, Xiaojian, and Edward J. W. Park, eds. Asian Americans: An Encyclopedia of Social, Cultural, Economic, and Political History. ABC-CLIO, 2013. 